This is the post print/pre print version of the article, which has been published in Future microbiology. 2018, 13 (7), 737-744, http://doi.org/10.2217/fmb-2017-0286.

\title{
Nature-derived microbiota exposure as a novel immunomodulatory approach
}

Noora Nurminen ${ }^{1}$

Jake Lin ${ }^{1,2}$

Mira Grönroos ${ }^{3}$

Riikka Puhakka ${ }^{3}$

Lenka Kramna ${ }^{4}$

Heli K. Vari ${ }^{3}$

Hanna Viskari ${ }^{1,5}$

Sami Oikarinen ${ }^{1}$

Marja Roslund ${ }^{3}$

Anirudra Parajuli ${ }^{3}$

liris Tyni ${ }^{1}$

Ondrej Cinek ${ }^{4}$

Olli Laitinen ${ }^{1 *}$

Heikki Hyöty ${ }^{1,6 *}$

Aki Sinkkonen ${ }^{3 *}$

1 Department of Virology, Faculty of Medicine and Life Sciences, University of Tampere, Arvo Ylpon katu 34, 33520 Tampere, Finland

2 Computational Biology, Faculty of Medicine and Life Sciences, University of Tampere, Arvo Ylpon katu 34, 33520 Tampere, Finland

3 Ecosystems and Environment Research Programme, Faculty of Biological and Environmental Sciences, University of Helsinki, Niemenkatu 73, 15140 Lahti, Finland

4 Department of Pediatrics, 2nd Faculty of Medicine, Charles University and University Hospital Motol, V Úvalu 84, Praha 5, 15006 Prague, Czech Republic.

5 Department of Internal Medicine, Tampere University Hospital, Teiskontie 35, 33520 Tampere, Finland 6 Fimlab Laboratories, Pirkanmaa Hospital District, Arvo Ylpön katu 4, 33520 Tampere, Finland.

*corresponding author

Correspondence to: Heikki Hyöty, heikki.hyoty@uta.fi

Keywords: microbial diversity, 16s rRNA, microbiome, immune-mediated diseases, biodiversity hypothesis, immune modulation 


\section{Abstract}

Aims: Current attempts to modulate the human microbiota and immune responses are based on probiotics or human-derived bacterial transplants. We investigated microbial modulation by soil and plant based material. Materials \& Methods: We performed a pilot study in which healthy adults were exposed to the varied microbial community of a soil and plant based material. Results: The method was safe and feasible, exposure was associated with an increase in gut microbial diversity. Conclusions: If these findings are reproduced in larger studies nature-derived microbial exposure strategies could be further developed for testing their efficacy in the treatment and prevention of immune-mediated diseases.

\section{Introduction}

An urban lifestyle and reduced exposure to diverse environmental microbes may disturb the development of immunoregulatory mechanisms and contribute to incidence of immunemediated diseases which has increased globally[1,2]. These suggested connections are supported by ecological studies showing differences in the diversity, abundance and composition of skin and gut microbiota of people living either in urban or rural areas[2]. Accordingly, many immune-mediated diseases are characterized by gut microbiome dysbiosis associated with an urban lifestyle[3]. All previously published intervention trials aiming at changing the human microbiota have been based on the use of only a single or a few bacteria (probiotics) $[4,5]$ or fecal and vaginal microbiome transplantations[6,7]. Exposure to few fastgrowing probiotics is strikingly different from the microbiota of natural soils characterized by high bacterial diversity and the predominance of dormant and slowly growing bacteria[8,9] that have become rare in urban environments. Here, we introduce a novel strategy for 
modulating the human microbiome and immune system using a nature-derived diverse microbiome including non-culturable and slowly growing bacteria.

\section{Materials and methods}

\section{Study groups, exposure and sampling}

Fourteen volunteers living in urban settings (healthy adults, age 27-63 years) participated in the safety and feasibility -oriented open trial using a case-control design. The medical exclusion criteria were the following: immune deficiencies, immunosuppressive medications, 3 or more infections within a year that required hospitalization, condition affecting the immune response (e.g. rheumatoid arthritis, colitis ulcerosa, Crohn's disease), memory disorder diagnosed by a medical doctor, acute depression or acute or earlier psychosis, cancer diagnosis within the last two years or on-going cancer treatment, type 1 or type 2 diabetes, rash or ulcers in hands. Other exclusion criteria included: living outside city area, age under 18 or over 65 , incompetency and daily smoking. All participants provided a written, informed consent. General immunological health status and protection against Clostridium tetani was confirmed before starting the experiment by analyzing complete blood count (CBC), differential blood count and serum Clostridium tetani tetanus toxoid antibodies from all study subjects in a certified hospital laboratory (Fimlab laboratories, Tampere, Finland). All subjects having a deviation from reference values in any of the analyzed were excluded from the study. A study nurse checked that the skin on the participants' hands was in good condition having no eczema or wounds before starting the trial. Approval to conduct the research was obtained from the ethical committee of the local hospital district (Pirkanmaa Hospital District, Finland). The study was conducted in accordance with the principle of the Helsinki Declaration. The trial has been registered in ClinicalTrials.gov (ID NCT03351543). 
The study subjects were divided into two groups which were similar in their gender, age, pet ownership, and dwelling type (apartment building, row house, detached house) distribution. One group followed the exposure protocol while the other was a non-exposed control group. The median age was 36 years (range $27-57$ years) in the intervention group and $28.6 \%$ were males. Corresponding figures in the control group were 42 years (range 28-63 years) and $28.6 \%$.

The exposure group conducted a two-week long exposure by rubbing their hands with a soil and plant based immunomodulatory composition three times per day: before breakfast, before dinner/evening snack, and before going to bed. The participants were instructed to rub the material into their hands for 20 seconds after which they washed their hands with tap water but without soap for five seconds and dab their hands dry with a towel. The material aliquot was replaced with a new aliquot in the middle of the exposure period.

The soil and plant based composition was manufactured by sieving and combining various composted Finnish soil and plant materials in the laboratory of environmental ecology, University of Helsinki. The general ingredients for these soil types were various compositions of industrial composts originating from raw materials such as cattle dung, horse dung, chicken dung, deciduous leaf litter, plant debris, horticultural peat, sludge, fine mineral soil such as silt as well as crushed tree bark mulch. Each major ingredient was sieved using a $\varnothing 5 \mathrm{~mm}$ sieve and each minor ingredient using a $\varnothing 2 \mathrm{~mm}$ sieve. Moss was dried, crushed and mixed thoroughly before mixing with other ingredients. Major ingredients, moss and minor ingredients were used so that eight parts of each major ingredient, two parts of moss and one part of each minor ingredient was mixed thoroughly. Figure 2c. contains the phylum 
operational taxonomy metrics, as detected using 16s rRNA sequencing of the soil and plant composition matter microbial composition.

The participants collected stool samples and skin swab samples from $5 \times 5 \mathrm{~cm}$ area of the volar surface of the forearm at home right before the exposure period (day 0), immediately after the exposure period (day 14), and three weeks after the exposure period (day 35) and stored the samples in a freezer until they had a study nurse visit few days later. The nurse collected blood samples and interviewed the subjects on each visit about their health status during the study period. In addition, adherence to the exposure protocol, adverse effects and potential life-style changes during the exposure period (e.g. nutrition, dietary supplements and medications) were recorded after the exposure period.

\section{The bacterial 165 rDNA amplicon profiling}

The total DNA was extracted from 30-60 mg of frozen unprocessed stool, or from skin swabs frozen in sterile swab solution $\left(0.15 \mathrm{M} \mathrm{NaCl}, 0.1 \%\right.$ Tween), both using PowerSoil ${ }^{\circledR}$ DNA Isolation Kit (formerly MoBio, now Qiagen, Hilden, Germany) according to the manufacturer's standard protocol. To establish the bacteriome profiles of samples, we used mass amplicon sequencing of the V4 region of $16 \mathrm{~S}$ rDNA. The primers sequences targeting this region were identical to $515 \mathrm{~F}$ and $806 \mathrm{R}$ primers described elsewhere[10]. After the amplicons tailed with sequencing adaptors had been generated, we purified them with Agencourt AMPure (Beckman), equalized their concentration, pooled and sequenced on a MiSeq instrument (Illumina). For compatibility with earlier projects using the same sample types, the pipelines of amplicon creation slightly differed between stool samples and skin samples; it has to be noted that the target region and primers were exactly identical, and so was the amplicon position in the $\mathrm{V} 4$ alignment. The stool samples were amplified using a grid of primers already 
synthesized with pad, linker, index and sequencing adaptors whereas the skin samples were first amplified with simple primers, and only then the amplicons were provisioned with the indices using a tag PCR, and with sequence adaptors using a ligation step. To control the process, Mock Community, which is a complex mix of bacterial DNA of a known content (courtesy of BEI Resources, please see Acknowledgements), a positive control (Enterococcus faecalis), and negative controls (water instead of sample) were utilized throughout the sequencing.

\section{Sequence processing}

Next-generation sequencing data from skin and stool were processed and analyzed using mothur (version 1.36.1)[11], custom python scripts, and QIIME[12]. The sequence processing protocol partly followed the pipeline suggested earlier $[13,14]$. The paired sequences contained in reverse and forward fastq files were aligned into contigs. Sequences were trimmed and screened to remove any mismatches with primer or DNA-tag sequences, ambiguous bases and homopolymers larger than $8 \mathrm{bp}$ long. Sequences were aligned using mothur version of SILVA bacterial reference sequences (version 102)[15] and the sequences which were not aligned to a reference alignment of the correct sequencing region were removed. Unique sequences and their frequency in each sample were identified and screened for chimeras (usearch academic version, http://www.drive5.com/usearch for stools, UCHIME[16] for skin and exposure material samples) using the abundant sequences as a reference. The chimeric sequences were removed. We calculated a pairwise distance matrix for unique sequences and clustered OTUs at $97 \%$ sequence similarity using the nearest neighbor algorithms. Sequences were classified using the Mothur version of Bayesian classifier[17] with the RDP training set version 9[18]. Sequences classified to 
Chloroplast, Mitochondria, unknown, Archaea and Eukaryota were removed from the analyses. Green genes[19] core imputed reference was further integrated for building phylogenetic tree required for further downstream statistical analysis. The exposure material from soil and plant composition were also processed using mothur and SILVA bacterial reference. While stool, skin and exposure material samples were sequenced in different batches, we aggregated OTUs up to phylum to be able to compare different sample types.

\section{Blood samples}

Blood samples were taken into Vacutainer ${ }^{\circledR} \mathrm{CPT}^{\mathrm{TM}}$ Mononuclear Cell Preparation tubes with sodium citrate (BD Biosciences, USA) and centrifuged according to manufacturer's instructions. The peripheral blood mononuclear cells (PBMCs) were snap frozen in liquid nitrogen and stored at $-80^{\circ} \mathrm{C}$.

\section{Real-time qPCR}

Cytokine mRNA expression in snap frozen PBMCs was measured using real-time qPCR. The RNA was extracted using RNeasy Mini Kit (Qiagen, Hilden, Germany) following the manufacturer's instructions and reversely transcribed into cDNA with oligo-dT and random hexamer primers using Promega M-MLV Reverse Transcriptase reagents (Promega, Madison, WI, USA). Primers for IL-10 (interleukin 10), TGF-b (transforming growth factor beta) and TBP (TATA-box binding protein, a housekeeping gene) were: forward: 5'-CAG TTT TAC CTG GAG GAG GTG-3', reverse: 5'-AGA TGC CTT TCT CTT GGA GCT TAT-3', forward: 5'-ACG TGG AGC TGT ACC AGA AAT AC-3', reverse: 5'-GTA GTG AAC CCG TTG ATG TCC-3', forward: 5'-CGA ATA TAA TCC CAA GCG GTT-3' and reverse: 5'-ACT TCA CAT CAC AGC TCC CC-3', respectively. The qPCR reaction mixture was prepared using DyNAmo Flash SYBR Green qPCR Kit (Thermo 
Fisher Scientific, Waltham, MA, USA) and ABI Prism ${ }^{\circledR} 7900$ HT (Applied Biosystems) apparatus according to the manufacturer's instructions. Gene expression values were normalized to the amount of TBP using previously described method[20].

\section{Statistical methods}

The $\mathrm{R}$ language platform was used for data integration and plotting. Key packages include the microbial packages phyloseq V16.2[21]and vegan[22] along with fold change estimation Deseq2[23]. The purpose of the statistical analyses was to find out whether the exposure led to shifts in bacterial diversity in fecal and skin samples and if the changes were associated with the differences in cytokine mRNA expression. Linear regression analysis was performed in IBM SPSS ver 24.0.

Differences in bacterial diversity between the exposed and controls were analyzed using Shannon diversity index as well as visually via relative phylum abundance plots over time periods in match group panels. Changes and rates of change between the start and the end of the exposure were especially important, as the composition change would provide directly comparable results to the exposure effects on gut and skin microbiome. Samples were subsampled to the minimum number of reads per sample to filter rare OTUs to preserve maximal bacterial diversity representation and to account for varying sample size when comparing diversity. All samples within the exposed and controls passed this threshold. The difference between bacterial composition in the samples before and after exposure was calculated using rate of change in Shannon diversity index between days 0 and 14 .

Rate of change of Shannon diversity index was tested using two-sided non-paired T-test and normal distribution was confirmed with a QQ-Plot (Supplementary Fig. 2). Phyloseq together with ggplot2[24] was used for relative abundance plotting. 
NCBI: sequence data have been deposited under study accession number PRJNA390051.

\section{Results}

\section{Study population and exposure}

We conducted an open pilot trial among 14 healthy adultsto evaluate the feasibility and safety of this exposure and to study whether it can modulate the skin and gut microbiome or the immune system. The exposure material included 861 OTUs ( $\geq 97 \%$ similarity) from 19 phyla based on 16S rRNA sequencing (Fig. 2c; the two most abundant phyla being Bacteroidetes and Proteobacteria). No changes in the microbial composition of the material were seen when the material was analyzed after it was used in the exposure.

The exposure was performed thrice a day for two weeks with high compliance (Fig $1 \mathrm{~b}$, Supplementary Table 1). Overall, the procedure was feasible and safe; minor inconveniences were messiness of the material (reported by $71 \%$ of participants), dirt under the nails and coloring (57\%) and drying of the hands (43\%) during the trial. No clinically relevant adverse effects (abrasions, cuts, ulcers, rash or other skin symptoms) were recorded.

\section{Microbiota composition and diversity}

Skin swabs, stool and blood samples were collected in order to study the possible changes in the microbiome (Fig. 1a). Sequencing of the bacterial 16S rRNA[14] showed that the alpha diversity of the stool microbiome increased during the exposure compared to controls $(p=0.029$; Fig. $2 b$ and Supplementary Fig. 2). The change seemed to be coupled with an increase in of the abundance of phyla Bacteroides. This increase was not seen in the control group (Supplementary Fig. 1.) There were no difference between the groups in alpha diversity 
before the exposure or three weeks after the exposure. In addition, the alpha diversity of the skin microbiome increased clearly in two individuals (red dots Fig. $2 b$ ) but the overall change was not significant. These two individuals experienced a stronger exposure than others in the intervention group; their hands were clearly colored after exposure as they washed their hands superficially and did not rub their hands dry with a towel afterwards (Supplementary Table 1). Furthermore, the microbial composition of the skin of these two individuals showed an increase of the phyla Bacteroidetes, Chlorflexi and Actinobacteria, which were abundant in the exposure material (Fig 2a and 2c.) although the phylum changes were not dramatic.

\section{Association of microbial diversity change to immune system markers}

Next, we compared the change in bacterial diversity in the exposure group to the expression of two immunoregulatory cytokines (TGF-beta and IL-10 mRNA) in peripheral blood mononuclear cells (PBMCs) at the end of the exposure period. The change in the bacterial diversity in both the skin and stool was associated with the level of TGF-beta expression right after the exposure period $\left(R^{2}=0.971, p=0.001\right.$, Supplementary Fig. 3$)$. However, bacterial diversity change did not correlate with IL-10 expression.

\section{Discussion}

The present trial is the first study in which a rich nature-derived preparation of diverse microbial composition is administered to humans in the form of a validated and processed nature-based material. The results suggest that even a short two-week exposure to this material can modulate the microbiome in urban dwellers whose contacts with microbiologically diverse and rich environments are otherwise limited. The change in the stool microbiome during the exposure implies that the exposure can modulate the microbiome relatively widely. Our previous studies indicate that this treatment clearly 
changes skin microbiome at the exposure site (Gronroos et al., unpublished observations). The present study suggests that this change can also spread to more distant skin areas when the local exposure has been intense enough: the two participants whose palm exposure was particularly intense had a clear change in skin diversity in the forearm skin. This could also be achieved by developing the application method.The potential of the tested exposure procedure is emphasized by the fact that previous trials using orally administered probiotic bacteria have not been able to demonstrate a clear change in the gut microbiome of healthy adults $[5,25]$.

\section{Conclusions}

Altogether, the results of this pilot study give reason to carry out larger,long-term, randomized, placebo-controlled and blinded trials to validate these findings and to evaluate the effects of this intervention on the immune system. More studies would also be needed to identify optimal application methods and delivery regimens. Provided the current findings are reproduced in larger studies, nature-derived microbial exposure strategies could be further developed for trials testing their efficacy in the treatment and prevention of immunemediated diseases.

\section{Future Perspective}

The understanding of the role human microbiome for the health is increasing rapidly. It is therefore likely that the modulation of microbiome becomes an important part of patient care as demonstrated by the success of fecal transplantations in restoring the healthy gut microbiome. In the future, the aims are to standardize the treatment regimens and tailor them for individual purposes. The long-term goal includes also the prevention of diseases, 
which introduces new challenges in terms of scalability and safety of these treatments. Prevention of immune-mediated diseases is a highly attractive target, as these diseases are increasing rapidly and affect a large proportion of population. The means used for the induction of beneficial immunological effects by microbial exposures should not be limited to the modulation of colonizing microbiome but cover also the stimulation of the immune system vial multiple routes using a wide range of microbe-associated molecular patterns. The currently described new regime, a daily exposure to the microbial diversity that is present in the nature, may offer one feasible way to introduce beneficial immunological effects to a large group of people in a safe way.

\section{Summary points}

- Many immune-mediated diseases are characterized by gut microbiome dysbiosis associated with an urban lifestyle. This has led to e.g. clinical probiotic intervention studies trying to modulate the microbiome diversity but these studies have lacked a demonstration of a clear change in the gut microbiome of healthy adults.

- We investigated gut and skin microbial modulation with soil and plant based material containing diverse microbial composition including also slowly growing bacteria lacking from probiotic interventions.

- We show that the method is a safe and feasible way of modulating the microbiome

- We demonstrate that the exposure was associated with an increase in gut microbial diversity and indicated also that skin microbiome could be changed with a more intensive exposure to the material. 
- In conclusion, nature-derived microbial exposure strategies have the potential to modulate gut and skin microbiome and they could be further developed for trials testing their efficacy in the treatment and prevention of immune-mediated diseases.

\section{Acknowledgements}

The authors wish to thank Minta Lumme and Karla Mazánková for their assistance in the laboratory analyses. The bacterial mock community was courtesy of BEI Resources, NIAID, NIH, as part of the Human Microbiome Project (Genomic DNA from Microbial Mock Community B - Even, Low Concentration - v5.1L, for 16S rRNA Gene Sequencing, HM-782D).

\section{Financial disclosure}

This work is supported by the Finnish Funding Agency for Innovation TEKES under the Large Strategic Opening project 'ADELE' (grant number 40333/14). A patent application "Immunomodulatory compositions" related to methods for modifying human microbiota has been filed on behalf of A.S., H.H., O.L., M.G., S.O. and N.N.

\section{References}

1. von Hertzen L, Beutler B, Bienenstock J et al. Helsinki alert of biodiversity and health. Ann. Med. 47(3), 218-225 (2015).

2. Haahtela T, Holgate $\mathrm{S}$, Pawankar $\mathrm{R}$ et al. The biodiversity hypothesis and allergic disease: world allergy organization position statement. World Allergy Organ. J. 6(1), 3 (2013).

* The paper introduces the biodiversity hypothesis.

3. Round JL, Mazmanian SK. The gut microbiota shapes intestinal immune responses during health and disease. Nat. Rev. Immunol. 9(5), 313-323 (2009).

4. Bridgman SL, Kozyrskyj AL, Scott JA, Becker AB, Azad MB. Gut microbiota and allergic disease in children. Ann. Allergy Asthma Immunol. 116(2), 99-105 (2016).

\footnotetext{
** The paper presents collected results of probiotic intervention studies against allergic diseases.
} 
5. McFarland LV. Use of probiotics to correct dysbiosis of normal microbiota following disease or disruptive events: a systematic review. BMJ Open 4(8), 005047 (2014).

6. Cohen NA, Maharshak N. Novel Indications for Fecal Microbial Transplantation: Update and Review of the Literature. Dig. Dis. Sci. 62(5), 1131-1145 (2017).

7. Dominguez-Bello MG, De Jesus-Laboy KM, Shen $\mathrm{N}$ et al. Partial restoration of the microbiota of cesarean-born infants via vaginal microbial transfer. Nat. Med. 22(3), 250-253 (2016).

8. Coyte KZ, Tabuteau H, Gaffney EA, Foster KR, Durham WM. Microbial competition in porous environments can select against rapid biofilm growth. Proc. Natl. Acad. Sci. U. S. A. 114(2), E170 (2017).

9. Kaiser C, Franklin O, Richter A, Dieckmann U. Social dynamics within decomposer communities lead to nitrogen retention and organic matter build-up in soils. Nat. Commun. 6, 8960 (2015).

10. Caporaso JG, Lauber CL, Walters WA et al. Ultra-high-throughput microbial community analysis on the Illumina HiSeq and MiSeq platforms. ISME J. 6(8), 1621-1624 (2012).

11. Schloss PD, Westcott SL, Ryabin T et al. Introducing mothur: open-source, platform-independent, community-supported software for describing and comparing microbial communities. Appl. Environ. Microbiol. 75(23), 7537-7541 (2009).

12. Caporaso JG, Kuczynski J, Stombaugh J et al. QIIME allows analysis of high-throughput community sequencing data. Nat. Methods 7(5), 335-336 (2010).

13. Schloss PD, Gevers D, Westcott SL. Reducing the effects of PCR amplification and sequencing artifacts on 16S rRNA-based studies. PLoS One 6(12), e27310 (2011).

14. Cinek O, Kramna L, Lin J et al. Imbalance of bacteriome profiles within the Finnish Diabetes Prediction and Prevention study: Parallel use of $16 \mathrm{~S}$ profiling and virome sequencing in stool samples from children with islet autoimmunity and matched controls. Pediatr. Diabetes (2016).

15. Pruesse E, Quast C, Knittel K et al. SILVA: a comprehensive online resource for quality checked and aligned ribosomal RNA sequence data compatible with ARB. Nucleic Acids Res. 35(21), 71887196 (2007).

16. Edgar RC, Haas BJ, Clemente JC, Quince C, Knight R. UCHIME improves sensitivity and speed of chimera detection. Bioinformatics 27(16), 2194-2200 (2011).

17. Wang Q, Garrity GM, Tiedje JM, Cole JR. Naive Bayesian classifier for rapid assignment of rRNA sequences into the new bacterial taxonomy. Appl. Environ. Microbiol. 73(16), 5261-5267 (2007).

18. Cole JR, Wang Q, Cardenas E et al. The Ribosomal Database Project: improved alignments and new tools for rRNA analysis. Nucleic Acids Res. 37(Database issue), 141 (2009).

19. DeSantis TZ, Hugenholtz $P$, Larsen N et al. Greengenes, a chimera-checked $16 \mathrm{~S}$ rRNA gene database and workbench compatible with ARB. Appl. Environ. Microbiol. 72(7), 5069-5072 (2006).

20. Pfaffl MW. A new mathematical model for relative quantification in real-time RT-PCR. Nucleic Acids Res. 29(9), e45 (2001). 
21. McMurdie PJ, Holmes S. phyloseq: an R package for reproducible interactive analysis and graphics of microbiome census data. PLoS One 8(4), e61217 (2013).

22. Oksanen J, Blanchet FG, Kindt R et al. vegan: Community Ecology Package. Ordination methods, diversity analysis and other functions for community and vegetation ecologists. Version 2.3-3. URL https://CRAN.R-project.org/package=vegan. (2016).

23. Love MI, Huber W, Anders S. Moderated estimation of fold change and dispersion for RNA-seq data with DESeq2. Genome Biol. 15(12), 550 (2014).

24. Wickham H: ggplot2: Elegant Graphics for Data Analysis. Springer-Verlag New York (2009).

25. Kristensen NB, Bryrup T, Allin KH, Nielsen T, Hansen TH, Pedersen O. Alterations in fecal microbiota composition by probiotic supplementation in healthy adults: a systematic review of randomized controlled trials. Genome Med. 8(1), 5 (2016).

\section{Ethical conduct of research}

The authors have obtained appropriate institutional review board approval and have followed the principles outlined in the Declaration of Helsinki for all human experimental investigations. In addition, informed consent has been obtained from the participants. 


\section{Figures}

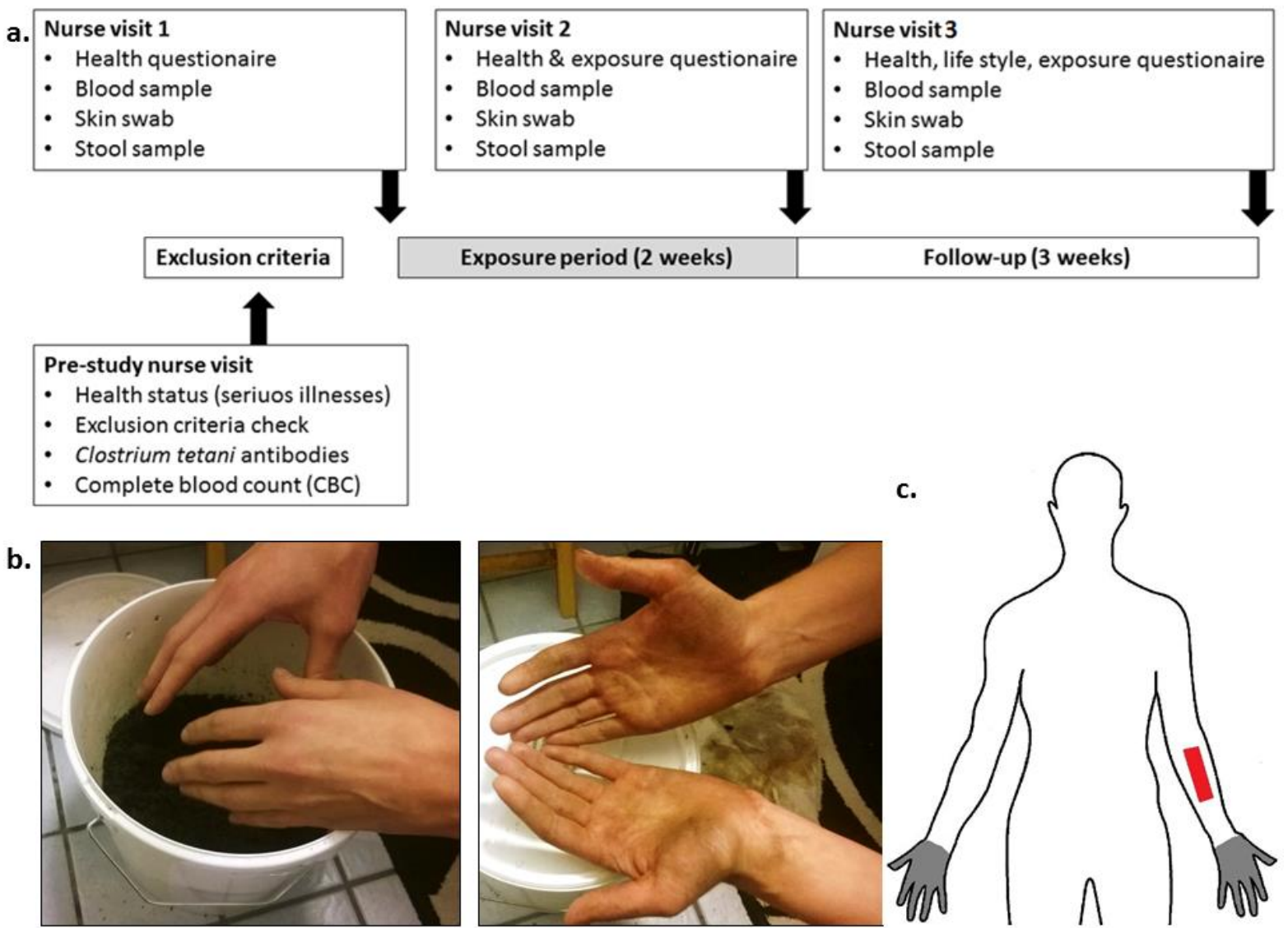

Figure 1. Study design and exposure. a. The study participants were interviewed and samples were taken before starting the exposure period (day 0), after the 2-week exposure period (day 14) and 3 weeks after the exposure period (day 35). b. The exposure group rubbed the exposure material in their palms 3 times per day during the exposure period (left). The hands were washed with water and dried in a paper towel after each treatment (right). c. A skin swab was taken from the center of volar surface of the forearm (red area). The hands were in direct contact with the exposure material (gray area). 


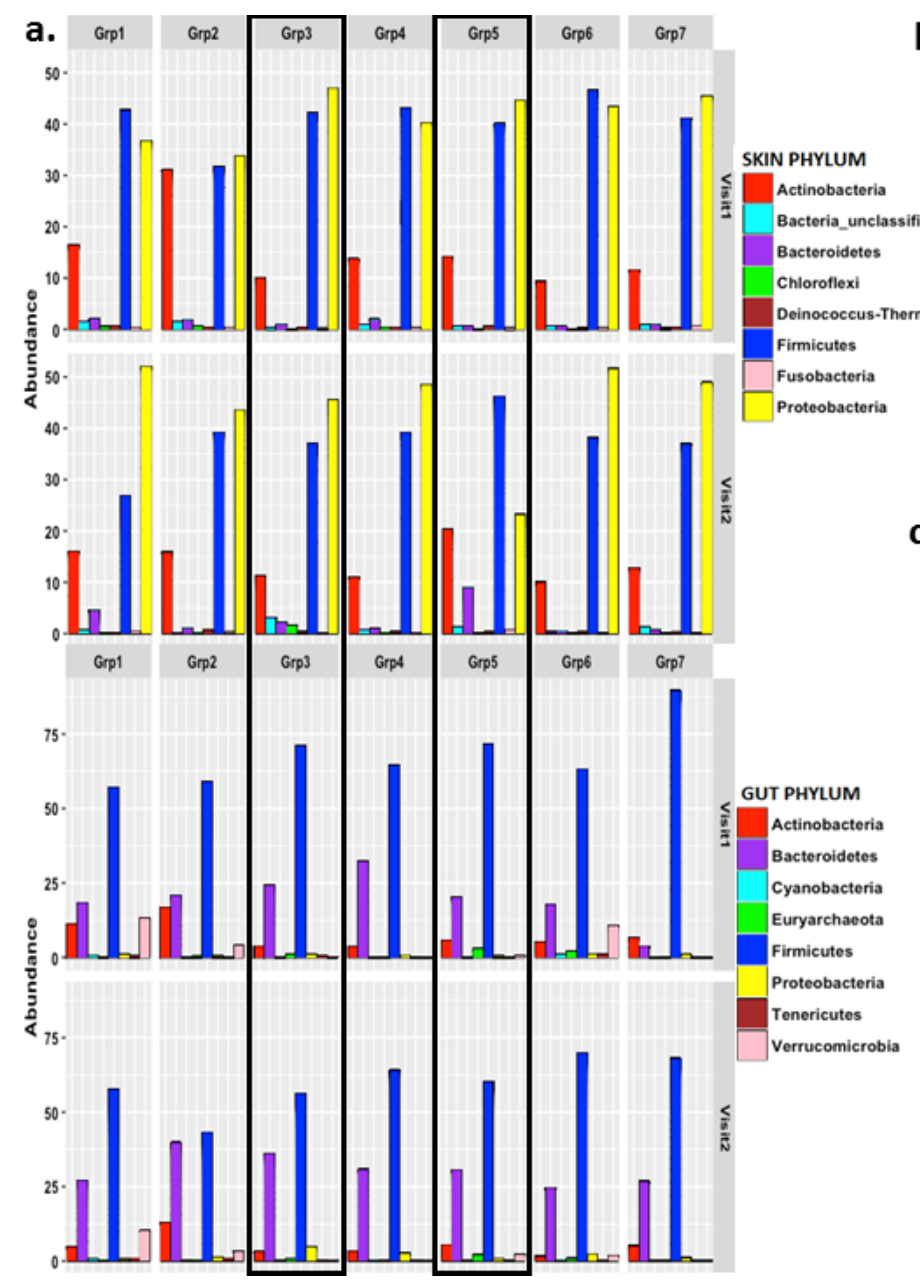

b. Shannon $\alpha$ diversity - Rate of change

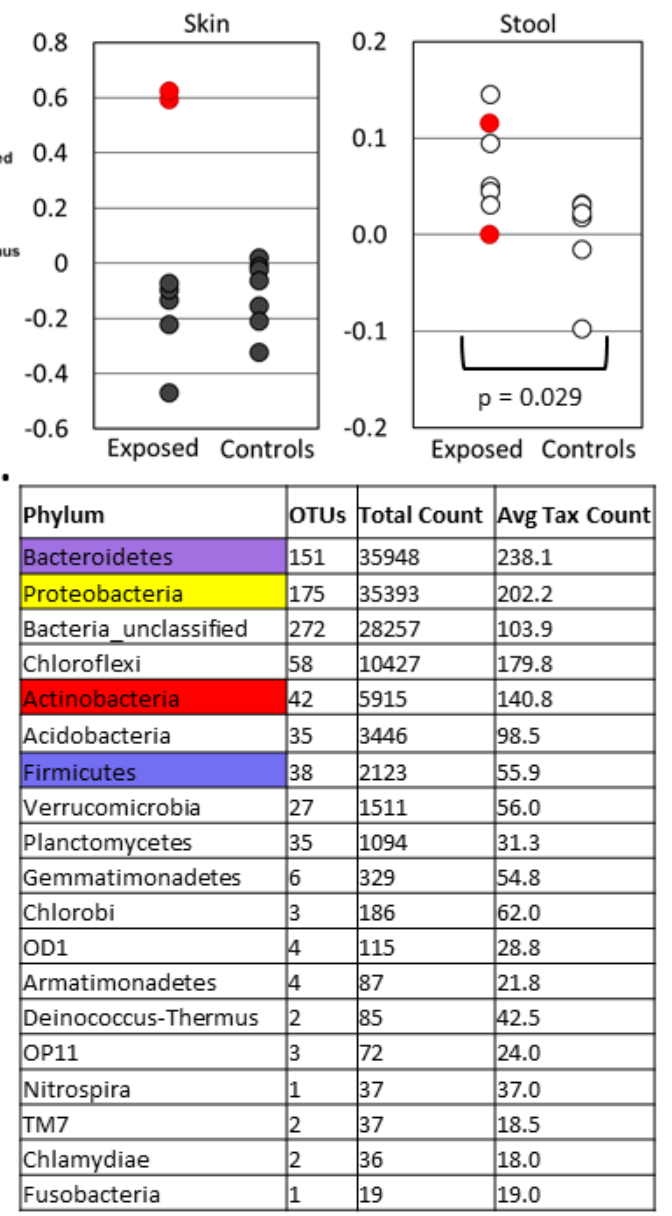

Figure 2. Skin and gut bacterial community changes during the exposure period. a. The plots show proportional abundance of top 8 phyla between time points prior (Visit 1) and immediately after the 2-week exposure period (Visit 2) in the skin (upper panel) and gut (lower panel) of the exposure group subjects (Grp1-Grp7). Heavily exposed individuals (Grp3 and Grp5) are marked with black frames. b. Rate of change in the Shannon $\alpha$-diversity of the skin (black dots) and the gut (white dots) after the exposure period. Heavily exposed individuals (Grp3 and Grp5) are marked with red dots. Change in gut $\alpha$-diversity is significantly higher in the exposure group than in the control group in unpaired t-test $(p=0.029)$. c. Phylum composition of the exposure material. For each phylum, number of OTUs, total number of reads and average number of reads per OTU are shown. 


\title{
Supplementary material
}

\section{Nature-derived microbiota exposure as a novel immunomodulatory approach}

\author{
Noora Nurminen ${ }^{1}$ \\ Jake Lin ${ }^{1,2}$ \\ Mira Grönroos ${ }^{3}$ \\ Riikka Puhakka ${ }^{3}$ \\ Lenka Kramna ${ }^{4}$ \\ Heli K. Vari ${ }^{3}$ \\ Hanna Viskari ${ }^{1,5}$ \\ Sami Oikarinen ${ }^{1}$ \\ Marja Roslund ${ }^{3}$ \\ Anirudra Parajuli ${ }^{3}$ \\ liris Tyni ${ }^{1}$ \\ Ondrej Cinek ${ }^{4}$ \\ Olli Laitinen ${ }^{1 *}$ \\ Heikki Hyöty ${ }^{1,6 *}$ \\ Aki Sinkkonen ${ }^{3 *}$
}

1 Department of Virology, Faculty of Medicine and Life Sciences, University of Tampere, Arvo Ylpon katu 34, 33520 Tampere, Finland

2 Computational Biology, Faculty of Medicine and Life Sciences, University of Tampere, Arvo Ylpon katu 34, 33520 Tampere, Finland

3 Ecosystems and Environment Research Programme, Faculty of Biological and Environmental Sciences, University of Helsinki, Niemenkatu 73, 15140 Lahti, Finland

4 Department of Pediatrics, 2nd Faculty of Medicine, Charles University and University Hospital Motol, V Úvalu 84, Praha 5, 15006 Prague, Czech Republic.

5 Department of Internal Medicine, Tampere University Hospital, Teiskontie 35, 33520 Tampere, Finland $33520 \mathrm{~T}$

*corresponding author

Correspondence to: Heikki Hyöty, heikki.hyoty@uta.fi

Keywords: microbial diversity, 16s rRNA, microbiome, immune-mediated diseases, biodiversity hypothesis, immune modulation 


\section{SUPPLEMENTARY FIGURES}

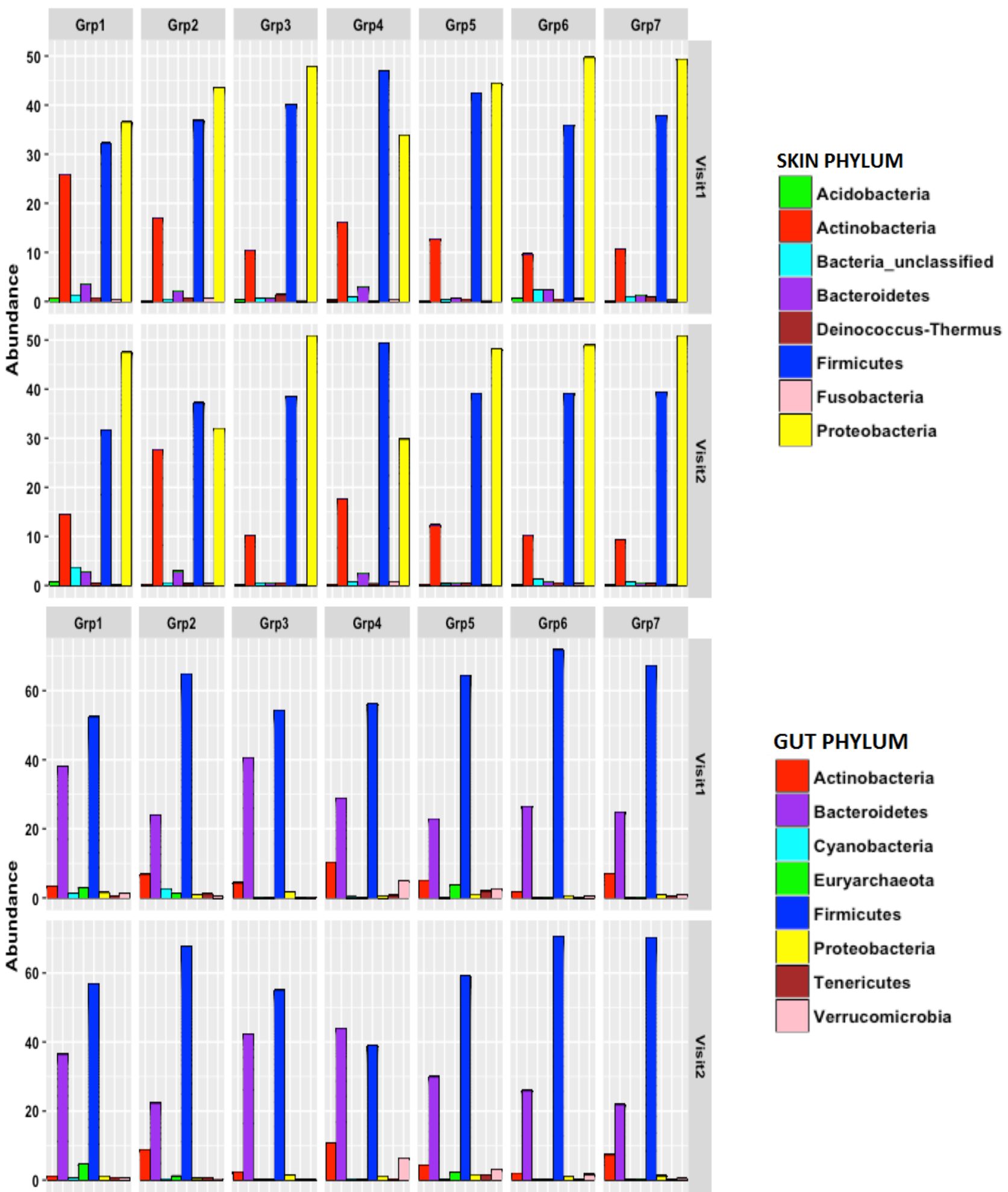

Supplementary Figure 1. Bacterial community changes over time in control group skin and stool microbial composition. The plots show proportional abundance of top 8 phyla between time points prior (Visit 1) and immediately after (Visit 2) the 2-week exposure period in the skin (upper panel) and gut (lower panel) of the control group subjects (Grp1Grp7). The plots show proportional abundance of top 10 phyla, accounting for $99 \%$ of reads, between time points prior and after exposure for each control subject. 


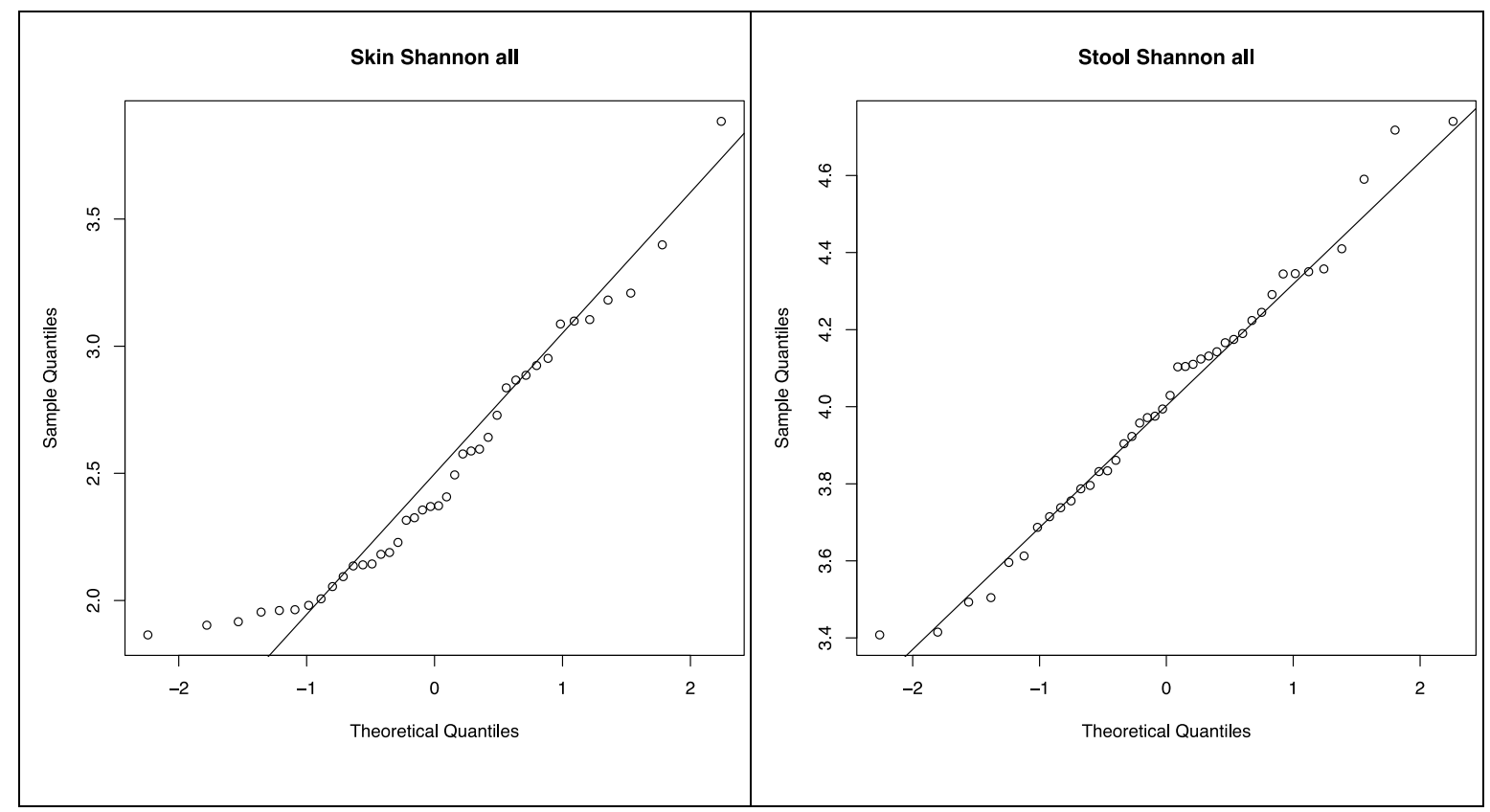

Supplementary Figure 2. QQ plots supporting Gaussian distribution. Shannon alpha diversity scores are plotted for skin (left) and stool (right) samples. With the exception of a few outliers, the distributions are normal. None of the data points were excluded from our statistical tests. 


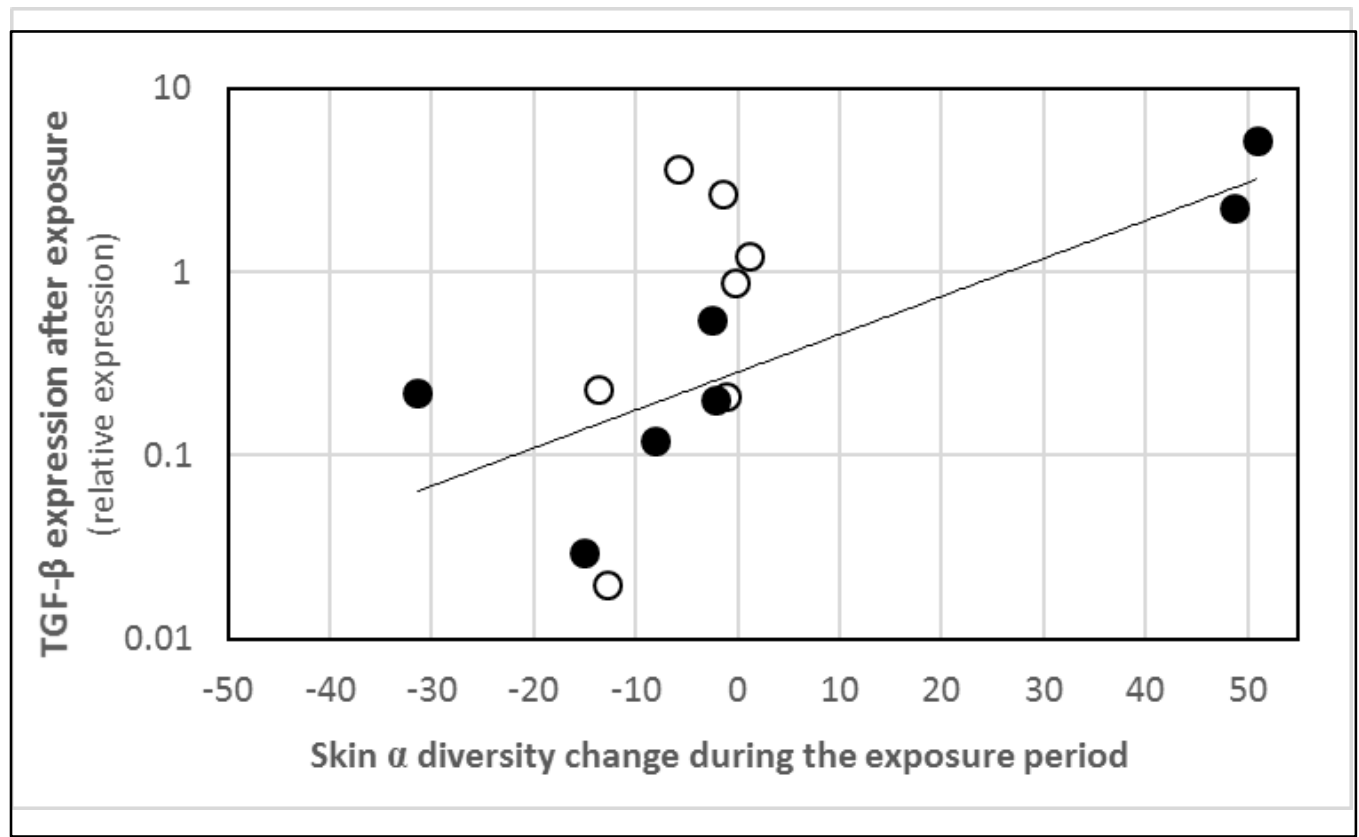

\begin{tabular}{|l|l|l|}
\hline & Exposure group & Control group \\
\hline Overall model, $\mathrm{N}=7$ & $\mathrm{R}^{2}=0.971, \mathrm{p}=0.001$ & $\mathrm{R}^{2}=0.241, \mathrm{p}=0.576$ \\
\hline & $\mathbf{p}$-value & $\mathbf{p}$-value \\
\hline (Constant) & 0.194 & 0.088 \\
\hline Skin alpha diversity change & $<0.0005$ & 0.355 \\
\hline Gut alpha diversity change & 0.005 & 0.428 \\
\hline
\end{tabular}

Supplementary Figure 3. Multivariable linear regression with relative TFG-b expression after exposure as dependent variable. The change in skin and stool diversity is associated with the level of TGF-beta expression after the exposure period. The figure illustrates correlation between skin alpha diversity change and TGF-beta expression level in exposed (black dots) and controls (open dots). 


\section{SUPPLEMENTARY TABLES}

Supplementary Table 1. Exposure questionnaire. Exposure questionnaire indicates deviation from the soil treatment protocol for $\mathrm{G} 3$ and $\mathrm{G} 5$ and the longest duration of visible soil on the hands (yellow cells)

\begin{tabular}{|c|c|c|c|c|c|c|c|c|c|c|c|c|}
\hline Subject & $\begin{array}{l}\text { Missed } \\
\text { soil } \\
\text { treatm } \\
\text { ents }\end{array}$ & \begin{tabular}{|l|} 
Instructed \\
treatment \\
time
\end{tabular} & $\begin{array}{l}\text { Water } \\
\text { wash } \\
\text { after } \\
\text { treatme } \\
\text { nt }\end{array}$ & $\begin{array}{l}\text { Soap } \\
\text { wash } \\
\text { after } \\
\text { treatm } \\
\text { ent }\end{array}$ & \begin{tabular}{|l|} 
Skipped \\
water \\
wash \\
after \\
treatme \\
nt
\end{tabular} & $\begin{array}{l}\text { Instructe } \\
\text { d water } \\
\text { wash } \\
\text { time (5 } \\
\text { sec) }\end{array}$ & \begin{tabular}{|l|} 
Drying \\
hands \\
after \\
water \\
wash \\
\end{tabular} & $\begin{array}{l}\text { Unpleasa } \\
\text { nt } \\
\text { sensation } \\
\text { s from } \\
\text { soil } \\
\text { treatmen } \\
\text { t }\end{array}$ & $\begin{array}{l}\text { Concrete negative } \\
\text { effects from soil } \\
\text { treatment }\end{array}$ & \begin{tabular}{|l|} 
Difficulties \\
performing soil \\
treatment
\end{tabular} & $\begin{array}{l}\text { Changes caused by } \\
\text { soil treatment (hands } \\
\text { and otherwise)? }\end{array}$ & $\begin{array}{l}\text { Duration } \\
\text { of } \\
\text { changes } \\
\text { reported } \\
\text { in the } \\
\text { previous } \\
\text { question } \\
\end{array}$ \\
\hline G1 & $\begin{array}{l}\text { Yes, } \\
\text { once }\end{array}$ & Yes & Yes & No & No & $\begin{array}{l}\text { Yes, 5-10 } \\
\text { sec. }\end{array}$ & $\begin{array}{l}\text { on a } \\
\text { towel }\end{array}$ & No & No & $\begin{array}{l}\text { Remembering } \\
\text { to do it was } \\
\text { sometimes } \\
\text { difficult } \\
\end{array}$ & No & - \\
\hline G2 & $\begin{array}{l}\text { Yes, } \\
\text { once }\end{array}$ & Yes & Yes & No & No & Yes & $\begin{array}{l}\text { on a } \\
\text { paper } \\
\text { towel }\end{array}$ & No & $\begin{array}{l}\text { The soil spreads into } \\
\text { the surroundings } \\
\text { from the bucket, } \\
\text { used a hand lotion } \\
\text { more than normally } \\
\text { just in case }\end{array}$ & $\begin{array}{l}\text { it was difficult } \\
\text { to remember all } \\
\text { the washes. }\end{array}$ & $\begin{array}{l}\text { Visible soil on the } \\
\text { skin }\end{array}$ & $\begin{array}{l}\text { Whole } \\
\text { time } \\
\text { between } \\
\text { the soil } \\
\text { treatment } \\
\text { s }\end{array}$ \\
\hline G3 & No & Yes & $\begin{array}{l}\text { Yes, but } \\
\text { after } 0,5 \\
\text { week } \\
\text { started } \\
\text { to only } \\
\text { rinse } \\
\text { the } \\
\text { hands } \\
\text { with } \\
\text { water }\end{array}$ & No & No & Yes & $\begin{array}{l}\text { dabbed } \\
\text { the } \\
\text { hands } \\
\text { on a } \\
\text { paper } \\
\text { towel } \\
\text { (not } \\
\text { really } \\
\text { drying } \\
\text { them) }\end{array}$ & No & $\begin{array}{l}\text { Visible soil under } \\
\text { the nails, the skin on } \\
\text { the hands was more } \\
\text { dry at first, soil } \\
\text { stayed visibly in the } \\
\text { folds of the skin on } \\
\text { the fingers (did not } \\
\text { rub the hands in the } \\
\text { paper while drying } \\
\text { them) }\end{array}$ & $\begin{array}{l}\text { the soil spreads } \\
\text { into the } \\
\text { surroundings } \\
\text { from the } \\
\text { bucket, the } \\
\text { bucket lid was } \\
\text { hard to open, } \\
\text { remembering to } \\
\text { do it was } \\
\text { difficult. }\end{array}$ & $\begin{array}{l}\text { Visible soil under the } \\
\text { nails, soil stayed } \\
\text { visibly in the folds of } \\
\text { the skin on the } \\
\text { fingers, the skin on } \\
\text { the hands was more } \\
\text { dry but it got better } \\
\text { after a while (used a } \\
\text { hand lotion the } \\
\text { whole period) }\end{array}$ & 3-4 days \\
\hline G4 & No & Yes & Yes & No & No & Yes & $\begin{array}{l}\text { on a } \\
\text { towel }\end{array}$ & No & $\begin{array}{l}\text { the skin on the } \\
\text { hands got more dry. } \\
\text { Got a runny nose at } \\
\text { the same time that } \\
\text { started to use the } \\
\text { soil, was wondering } \\
\text { whether it was a } \\
\text { coincidence }\end{array}$ & $\begin{array}{l}\text { the soil spreads } \\
\text { into the } \\
\text { surroundings } \\
\text { from the bucket }\end{array}$ & $\begin{array}{l}\text { Visibe soil stains in } \\
\text { the hands, visible soil } \\
\text { under nails, it made } \\
\text { the skin more dry } \\
\text { than usual (hand } \\
\text { lotion in use the } \\
\text { whole time) }\end{array}$ & $\begin{array}{l}\text { They } \\
\text { dissapear } \\
\text { ed as soon } \\
\text { as I } \\
\text { stopped } \\
\text { to use the } \\
\text { soil }\end{array}$ \\
\hline G5 & $\begin{array}{l}\text { Yes, } 4 \\
\text { times }\end{array}$ & Yes & Yes & No & No & $\begin{array}{l}\text { Yes, 5-10 } \\
\text { sec. }\end{array}$ & $\begin{array}{l}\text { Mostly } \\
\text { I didn't } \\
\text { dry the } \\
\text { hands }\end{array}$ & No & $\begin{array}{l}\text { Hands left marks on } \\
\text { surfaces (light } \\
\text { switches etc.), the } \\
\text { soil spreads into the } \\
\text { surroundings from } \\
\text { the bucket, visible } \\
\text { soil under nails }\end{array}$ & $\begin{array}{l}\text { It's hard to } \\
\text { travel while } \\
\text { performing the } \\
\text { soil treatments }\end{array}$ & Soil under the nails & about $24 \mathrm{~h}$ \\
\hline G6 & $\begin{array}{l}\text { No, but } \\
\text { I did it } \\
\text { a bit } \\
\text { later } \\
\text { than in } \\
\text { the } \\
\text { schedu } \\
\text { le on } \\
\text { few } \\
\text { occatio } \\
\text { ns }\end{array}$ & Yes & Yes & No & No & Yes & $\begin{array}{l}\text { on a } \\
\text { paper } \\
\text { towel }\end{array}$ & No & $\begin{array}{l}\text { the skin on the } \\
\text { hands got more dry } \\
\text { (used a hand lotion } \\
1-2 x \text { day) }\end{array}$ & $\begin{array}{l}\text { Remembering } \\
\text { to do it was } \\
\text { sometimes } \\
\text { difficult, the } \\
\text { soil spreads into } \\
\text { the } \\
\text { surroundings } \\
\text { from the } \\
\text { bucket, the } \\
\text { bucket lid was } \\
\text { hard to open at } \\
\text { first }\end{array}$ & $\begin{array}{l}\text { Skin in the hands was } \\
\text { more dry than usually }\end{array}$ & $\begin{array}{l}\text { a couple } \\
\text { of days }\end{array}$ \\
\hline G7 & $\begin{array}{l}\text { Yes, } 3 \\
\text { times }\end{array}$ & Yes & Yes & No & No & Yes & \begin{tabular}{|l|} 
rubbed \\
them \\
with \\
paper \\
towel
\end{tabular} & No & $\begin{array}{l}\text { No (used hand } \\
\text { lotion just in case) }\end{array}$ & $\begin{array}{l}\text { Remembering } \\
\text { to do it was } \\
\text { sometimes } \\
\text { difficult }\end{array}$ & No & - \\
\hline
\end{tabular}

